\title{
Medical Students' Perceptions of Their Learning Environment, Well-Being and Academic Self-Concept
}

\author{
Topi Litmanen ${ }^{1}$, Sofie M. M. Loyens ${ }^{2}$, Kirsi Sjöblom¹, Kirsti Lonka ${ }^{1}$ \\ ${ }^{1}$ Research Group of Educational Psychology, Department of Teacher Education, University of Helsinki, Helsinki, \\ Finland \\ ${ }^{2}$ Department of Psychology, Erasmus University Rotterdam, Rotterdam, The Netherlands \\ Email: ${ }^{\text {topi.litmanen@helsinki.fi }}$
}

Received 6 September 2014; revised 2 October 2014; accepted 16 October 2014

Copyright (C) 2014 by authors and Scientific Research Publishing Inc.

This work is licensed under the Creative Commons Attribution International License (CC BY). http://creativecommons.org/licenses/by/4.0/

c) $\underset{\mathrm{EY}}{\text { (i) Open Access }}$

\section{Abstract}

This study investigated medical students' perceptions of their learning environment and how these related to well-being in terms of experienced exhaustion and losing interest in personal studies. The goal was to also examine whether students' perceptions and experiences of well-being related to their academic self-concept. Experiences were compared between lecture-based learning (LBL) and problem-based learning (PBL) environments. The MED NORD questionnaire was used to measure students' experiences of their learning environment, experienced well-being (i.e. exhaustion and lack of interest) and academic self-concept. A total of 610 students participated. Structural equation modelling was used to investigate relationships between the variables under study. A cross-sectional design was used to compare experiences between different medical schools. Worry about future workload was found to positively relate to exhaustion, whereas worry and study satisfaction both negatively related to lack of interest. Experienced high workload related to both exhaustion and lack of interest. In turn, lack of interest was negatively related to academic self-concept, whereas exhaustion was positively related to it. PBL students reported higher levels of worry concerning future workloads, but they also experienced receiving more feedback. In addition, novice PBL students experienced higher levels of exhaustion and better academic self-concept than LBL students. No such differences were found between students in the clinical phase. Lack of interest concerning personal studies appeared to be more unfavourable than experiences of exhaustion, because the former was related to low academic self-concept. The PBL environment appeared challenging, but only during the first years of study.

\section{Keywords}

Problem Based Learning, Undergraduate Medical Education, Structural Equation Modelling,

\footnotetext{
"Corresponding author.
}

How to cite this paper: Litmanen, T., Loyens, S. M. M., Sjöblom, K., \& Lonka, K. (2014). Medical Students' Perceptions of Their Learning Environment, Well-Being and Academic Self-Concept. Creative Education, 5, 1856-1868. 


\section{Student Perception, Well-Being}

\section{Introduction}

The purpose of medical education is to offer students an empowering and engaging environment to practice their skills of advocating health and caring for the sick (WFME, 2003). Medical students enter medical school aiming to learn the skills required for being a doctor, and they are equipped with competencies they have acquired during their secondary education. In medical school, the aim to learn a doctor's skill set and previously acquired competencies are confronted with new academic demands.

The perceived learning environment, when defined not only as the physical setting of the medical school, but also as its social norms, atmosphere, and characteristics, has implications for students' well-being and study success (Genn, 2001). For example, dissatisfaction with the learning environment, high workload and insufficient feedback are associated with problems with well-being (Dahlin et al., 2010; Dyrbye et al., 2009; Salanova et al., 2010). On the other hand, satisfaction with the learning environment and support from peers and senior doctors helps medical students in achieving a higher academic performance and protects them from stress (Abdulghani et al., 2014; Tyssen et al., 2005) and exhaustion (Dahlin et al., 2010). However as Dyrbye et al. (2009) conclude, additional research is needed to determine how to create a learning environment that cultivates students' professional development while minimizing problems with their well-being. In this study we studied perceptions of the learning environment with five constructs: 1) Worry about future workload, i.e. how the student sees his future occupation; 2) Satisfaction with the learning environment, i.e. whether the student feels being in the right place; 3) Disengagement, i.e. an experience of a poor learning climate; 4) Workload, i.e. the experienced pace of one's studies; and 5) Feedback, i.e. encouragement and feedback from teachers.

\subsection{Students' Well-Being during Medical Education: Exhaustion and Lack of Interest}

Medical students seem to have a higher level of engagement in their studies than students of other fields (Salmela-Aro \& Kunttu, 2010), which may be due to the strict selection procedures in medical schools and the highly complex nature of the field. On the other hand, as a learning environment, medical education seems to be a demanding and overwhelming experience for many students. Compared to the general population, medical students experience higher levels of psychological distress (Benbassat, 2014; Dyrbye et al., 2006). While some amount of stress is desirable as a sign of study commitment (Kember \& Leung, 2006), high distress levels during personal studies are related to poor academic performance (Stewart et al., 1999) and declining empathy (Thomas et al., 2007). However, as long as the student is deeply interested in medicine, this appeal may keep him or her motivated despite the experienced distress. Particularly detrimental is losing interest in studying, which is often associated with lower grades and slower study progress (Mäkinen et al., 2004), and to considerations of interrupting scientific studies among Ph.D. students (Stubb et al., 2012). Diminished interest reflects an increasingly cynical attitude towards studying and losing the general meaning of the subject matter. Such an attitude combined with feelings of exhaustion may result in burnout, which develops over a long period of time. Burnout is prevalent among physicians in working life (Shanafelt et al., 2003), and its' consequences are severe (Taris, 2006). Although burnout has not been frequently reported among medical school students (Dyrbye et al., 2006), the risk factors (i.e. diminished interest and feelings of exhaustion) may arise during medical education and its' development may already begin during this phase (Dahlin et al., 2010; Krakowski, 1982; Wolf et al., 1989). The risk factors of burnout manifest themselves during education as having a cynical, detached, and uninterested attitude toward one's studies and feeling exhausted because of the study demands.

\subsection{Academic Self-Concept}

Academic self-concept is characterized as how a student perceives his/her personal academic ability. Academic self-concept is formed through experiences with the learning environment and is heavily dependent on the social comparison of self to others as a frame of reference (Bong \& Skaalvik, 2003; Marsh, 1987). Academic self-concept, in addition to performance, may suffer due to exhaustion and lack of interest. Academic self-concept is re- 
lated to both actual achievement (Hansford \& Hattie, 1982; Ma \& Kishor, 1997) and well-being (Skaalvik \& Rankin, 1995; Skaalvik, 1997). Medical schools are high-ability environments with a highly selected student population. Obtaining a weak sense of academic accomplishment in comparison to other medical students can be a particularly stressful experience in the context of medical education.

\subsection{Problem-Based and Lecture-Based Learning}

In medical schools, two instructional formats are commonly used, namely traditional, lecture-based instruction (LBL) or problem-based learning (PBL). PBL is characterized by small groups working on open-ended problems, which simulate real-life clinical cases. PBL effects on students' knowledge and skills seem positive when compared to conventional, lecture-based instruction (Schmidt et al., 2009). On the other hand, PBL requires self-directed learning skills, which some students may not yet possess when entering medical school.

But does PBL have effects on students' well-being? No differences have been found on measures of depression between PBL and non-PBL students (Camp et al., 1994). During the first two years of medical school, however, PBL has been associated with uncertainty about faculty expectations and appropriate study behaviours, unclear curricular demands, and concerns with assessment (Lewis et al., 2009; Moffat et al., 2004). On the other hand, PBL students have been found to be more satisfied with their learning environment and study conditions, and they reported receiving more feedback from teachers when compared to a traditional curriculum (Kiessling et al., 2004). Nevertheless, perceptions of the learning environment seem to change over time (Loyens et al., 2009), but research on how they change in a PBL environment among medical students is scarce. The present study tried to fill this gap by comparing students' well-being in both LBL and PBL environments, taking into account different phases of the medical education program (i.e., preclinical and clinical).

\subsection{The Present Study}

The first goal of our study was to investigate medical students' perceptions of their learning environment (i.e., worry about future workload, satisfaction, disengagement, workload, and feedback), how these relate to students' well-being (i.e., exhaustion and lack of interest) among medical students, and how these, in turn, relate to students' academic self-concept. Hence, our first research question was: How are students' perceptions of the learning environment, students' well-being, and their academic self-concept related? A structural equation model with exhaustion and lack of interest as mediators between the perceptions of the learning environment and academic self-concept was constructed. Academic self-concept, as being a comparison of personal capabilities in relation to other students reflects the perception of self in the educational environment. It is a result of the fit between the learner and the learning environment, and was chosen as the dependent variable in the model. Furthermore, it is tested whether exhaustion and lack of interest operate as mediating variables between perceptions of the learning environment and academic self-concept. Before testing the hypothesized model, we first conducted a confirmatory factor analysis (CFA) to assure the suitability of the used MED NORD (Lonka et al., 2008) questionnaire.

Based on previous research (Dahlin et al., 2010), we hypothesized that the perception of worry would positively relate to exhaustion while satisfaction with the learning environment would negatively relate to it. In addition, we hypothesized that lack of interest would negatively relate to academic self-concept, since previous research has established this relationship (Skaalvik, 1997).

The second goal of our study was to compare students' perceptions of their learning environment, exhaustion, lack of interest, and academic self-concept in PBL and LBL curricula and during different phases of medical education (pre-clinical and post-clinical phases). As mentioned earlier, effects of PBL on students' well-being are not unequivocal, since both uncertainty and satisfaction with the learning environment have been reported in earlier research. However, the phase of the program a student is enrolled in, also comes into play in this respect (e.g. Loyens et al., 2009). Therefore, our second research question was: Do students' perceptions of the learning environment, well-being (i.e., exhaustion and lack of interest), and academic self-concept differ in PBL and LBL curricula and in the pre-clinical versus clinical phase of the program? Based on previous research (Kiessling et al., 2004; Lewis et al., 2009; Moffat et al., 2004), we hypothesized that novice students report more workload and exhaustion in the PBL environment. On the other hand, we also anticipated that students in the PBL environment report to receive more feedback, as a perception of their learning environment. 


\section{Methods}

\subsection{Participants and Procedure}

Participants were 610 medical students (69\% male, 31\% female) from three medical faculties in Finland. The mean age was 23.2 years $(\mathrm{SD}=3.1)$. Because the study language is Finnish, the participants were ethnically a homogenous group. The first $(n=194)$ and second medical school $(n=240)$ have a lecture-based (LBL) curriculum. Of the students in the LBL medical schools, 251 were in the pre-clinical phase of their studies $\left(1^{\text {st }}\right.$ and $2^{\text {nd }}$ year of the programme) and 183 in their clinical phase $\left(3^{\text {rd }}\right.$ to $6^{\text {th }}$ year of the programme). The third medical faculty $(n=176$, pre-clinical $n=90$, clinical $n=86)$ had a PBL curriculum.

Data for this study were gathered using the MED NORD (Lonka et al., 2008) questionnaire, which was mailed to those students as stated as studying for first or fourth year at the medical faculty. They were informed that the materials concerned a study on student views of learning and studying. The questionnaire included 133 items and a background section, and took approximately 30 minutes to complete. Participation was voluntary and responses were analysed anonymously. Of the 735 students who received the questionnaire, 610 returned it (i.e. a response rate of $83 \%$ ). The students were informed that those who returned the questionnaire would receive a movie ticket voucher as a reward.

\subsection{The Learning Environments in Which the Study Took Place}

Entry to medical education in Finland is through an entrance examination. From those who take part in the examination about $10 \%$ to $15 \%$ get in and therefore the students constitute a highly selected group. Medical education in Finland is 6 years in duration. The first two years focus on preclinical phase and topics about normal development and thereafter the focus is on clinical medicine and patient cases. Data for this study were gathered in three of the five medical schools in Finland. The curriculum in the first lecture based medical school is built around periods, which have a particular theme and in the end of each period students take part in an exam or other evaluation method. Teaching methods comprise of lectures, laboratory work, demonstrations and eLearning. The second lecture based medical school has a traditional school like curriculum with lectures and laboratory work, and an emphasis in working in hospitals and health centres. In addition to exams, evaluation is done through portfolios. The third problem-based medical school applies the approach of seven steps (i.e., Seven Jump, Schmidt, 1983): 1) Clarify terms and concepts; 2) Define the problem; 3) Analyse the problem; 4) Draw a systematic inventory of explanations; 5) Formulate learning objectives; 6) Collect additional information; 7) Synthesize and test the acquired information. Evaluation is done mostly through logbooks, self-evaluations, and exams.

\subsection{Materials}

The MED NORD (Lonka et al., 2008) questionnaire was designed to measure several aspects related to student well-being and perceptions of the learning environment. Our study focused on a particular section of the MED NORD, namely a brief version of the Higher Education Stress Inventory (HESI), designed to capture a variety of stressful aspects and other conditions of the learning environment and that can be applied to different higher educational settings (Dahlin, 2007).

The MED NORD includes five HESI scales, which consist of a total of 18 items (Dahlin et al., 2005): disengagement (e.g. "Education produces anonymity and isolation among students"), receiving feedback (e.g. "Teachers give feedback on students' knowledge and competence"), workload (e.g. "Course literature is too difficult and extensive"), worry (e.g. "I am worried about being able to master the pool of knowledge required in my future profession") and satisfaction (e.g. "Teachers treat me with respect"). Two HESI scales, low commitment and financial concerns, were not included in the MED NORD. All items were rated on a 4-point Likert scale ranging from 1 (not true at all) to 4 (very true).

Participants' experiences of exhaustion and lack of interest were also included additionally to the HESI scales. Exhaustion (e.g. "I feel I am studying too hard") was measured by four items that were taken from occupational health research and modified to fit higher education studies (Maslach \& Jackson, 1981). Lack of interest (e.g. "The contents of my studies do not interest me") was measured by two items (Mäkinen et al., 2004). The exhaustion and lack of interest items were measured on a 5-point Likert scale ranging from 1 (not true at all to 5 (very true). 
Finally, academic self-concept was measured by asking participants to position themselves compared to their peer students. Respondents were asked to indicate whether their typical grade was worse than the average grade of their class, approximately the same as the average of their class, or better than average. These were coded as 1,2 and 3, respectively. In a previous study with a similar non-medical student sample, the correlation between this item and actual GPA was 0.63 (Nieminen, 2011).

\subsection{Analyses}

Before running the analyses, data were screened for missing values and each item was checked for normality. Missing value analysis revealed that one item belonging to the subscale disengagement, (i.e. "I am being less well treated because of my ethnic background") had 208 missing values (31.7\%). The distribution was also highly skewed towards disagreeing with the statement $(\mathrm{M}=1.15, \mathrm{SD}=0.44)$. Students in Finnish medical schools have a rather similar ethnic background and participants probably did not experience the question as relevant to them. This item was therefore deleted from further analyses. Those participants who had not answered the item about academic self-concept $(n=28)$, were dropped out. One other item (i.e. "My personal values are in conflict with the professional role mediated by the education") had eight missing values (1.1\%), while all other items had four $(0.7 \%)$ missing values or less. Missing values $n=25(0.2 \%$ of all values $)$ were replaced using the EM method in SPSS.

After data screening, a confirmatory factor analysis was used to validate the hypothesised survey structure of the MED NORD. The reliability of the latent constructs was assessed using coefficient $\mathrm{H}$ (Hancock \& Mueller, 2001) and descriptive statistics were calculated. After these preliminary analyses, a model was estimated using structural equation modelling (SEM) to investigate the relationships between student perceptions of the learning environment, well-being (i.e. lack of interest and exhaustion) and academic self-concept. Experience differences between PBL and non-PBL students were finally analysed with a multivariate analysis of variance (MANOVA).

For the CFA and SEM, four different fit indices were used: the conventional $\chi^{2}$, the Comparative Fit Index (CFI) (Bentler, 1990), the Tucker-Lewis Index (TLI) (Tucker \& Lewis, 1973) and the Root Mean Square Error of Approximation (RMSEA) (Browne \& Cudeck, 1993), as suggested by Schreiber et al. (Schreiber et al., 2006). For the $\chi^{2}$, a non-significant result indicates a good model fit. However, $\chi^{2}$ is affected by sample size and is very restrictive. A ratio of $\chi^{2}$ and the accompanying degrees of freedom is therefore used. A ratio of 3 or less indicates a suitable fit. The CFI and TLI range from 0 to 1 , with higher values indicating a better fit. Values greater than 0.90 are associated with an acceptable fit and values are greater than 0.95 with a well-fitting model. RMSEA values of 0.05 or less indicate a good fit, whereas values smaller than 0.08 are still indicative of an acceptable fit. Values greater than 0.10 should lead to model rejection (Browne \& Cudeck, 1993). The RMSEA was reported with $90 \%$ confidence intervals.

Finally, $\Delta \chi^{2}$ tests were used to evaluate the three-level structure (i.e., the mediating role of lack of interest and exhaustion). Alternative hierarchical models were constructed without direct paths between the HESI scales and academic self-concept. The $\Delta \chi^{2}$ statistic reflects the difference between the $\chi^{2}$ values of the two hierarchical models, its degrees of freedom equals the difference in the two models' degrees of freedom. A non-significant value of $\Delta \chi^{2}$ suggests that the overall fits of the two models are similar. With respect to the mediating, regulation variables, this implies that a completely mediated relation between students' conceptions and processing strategies by regulation activities is supported. A significant value of $\Delta \chi^{2}$ supports retention of the direct paths and therefore implies a partially mediated relationship between the perceptions of the learning environment and academic self-concept level by exhaustion and lack of interest (Kline, 2005).

After the SEM analysis, differences between the LBL and PBL programs were investigated using a MANOVA analysis. Data were analysed using a two-way MANOVA, with two medical schools (LBL and PBL) and study phases (pre-clinical and clinical) as independent between-subject factors, and disengagement, feedback, workload, worry, satisfaction, exhaustion, lack of interest and academic self-concept as dependent variables. Following Cohen (1988), partial $\eta^{2}=0.01$ was interpreted as small, partial $\eta^{2}=0.06$ as medium, and partial $\eta^{2}=$ 0.14 as large effect size. The CFA and SEM analyses were conducted using AMOS 18.0 and all other analyses were performed using SPSS 18.0.

\section{Results}

Table 1 reports the descriptive statistics of the five HESI scales measuring perceptions of the learning environ- 
Table 1. Descriptive statistics, Coefficient $\mathrm{H}$ and Pearson correlations for the study variables $(\mathrm{n}=610)$.

\begin{tabular}{cccccc}
\hline Variable & \multicolumn{3}{c}{ Descriptive Statistics } \\
\cline { 2 - 5 } & Scale & Mean & SD & Items, $\mathbf{n}$ & Coefficient H \\
\hline 1 Worry & $1-4$ & 2.79 & 0.75 & 3 & 0.78 \\
2 Satisfaction & $1-4$ & 3.37 & 0.38 & 5 & 0.66 \\
3 Disengagement & $1-4$ & 1.69 & 0.48 & 5 & 0.64 \\
4 Workload & $1-4$ & 2.12 & 0.68 & 2 & 0.65 \\
5 Feedback & $1-4$ & 1.99 & 0.63 & 2 & 0.89 \\
6 Exhaustion & $1-5$ & 2.61 & 0.87 & 4 & 0.71 \\
7 Lack of Interest & $1-5$ & 1.80 & 0.84 & 2 & 1 \\
\hline
\end{tabular}

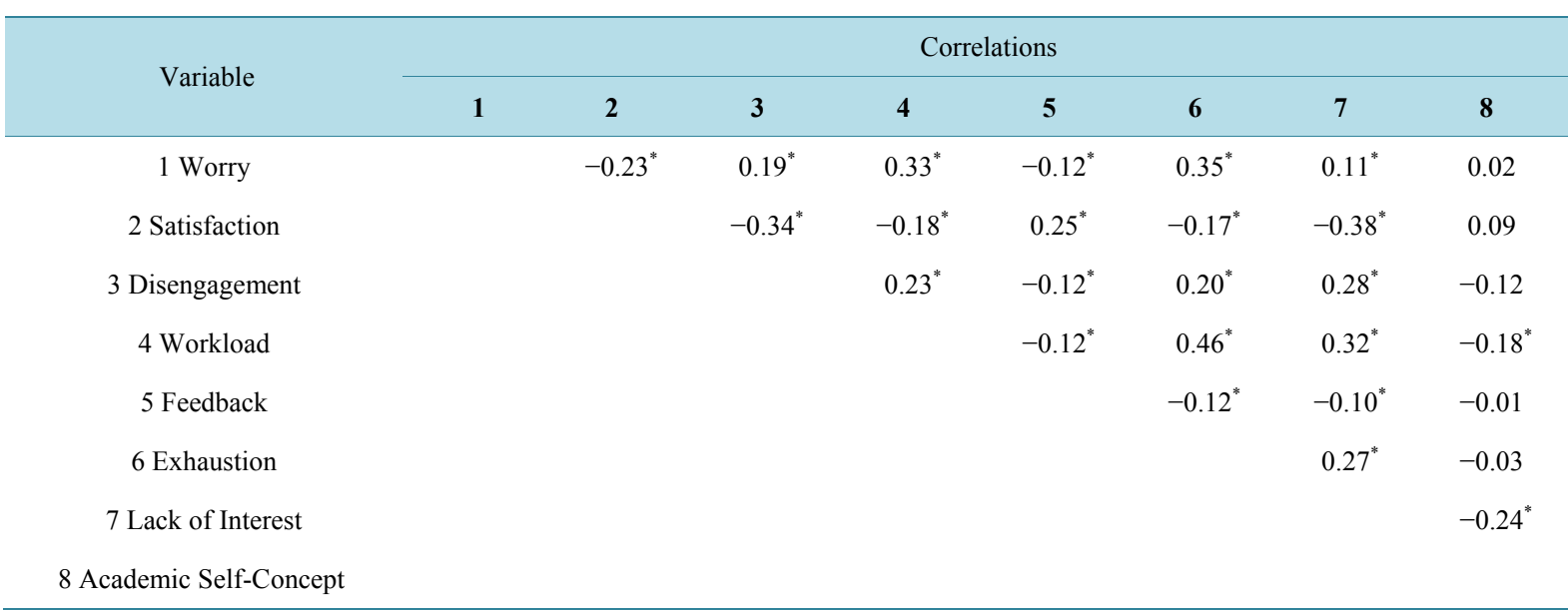

${ }^{*}$ Correlation is significant at the 0.01 level.

ment (i.e. worry, satisfaction, disengagement, workload and feedback) together with lack of interest and academic self-concept. The scores were highest concerning satisfaction with the learning environment, and also rather high concerning worry and workload. This implies that students were mostly satisfied with their learning environment, but they were also somewhat worried about their future competence and experienced high workload. Furthermore, their reported exhaustion scores were higher than their lack of interest scores, but both scales indicated quite healthy measures in general. High levels of lack of interest were quite rare.

Correlations between the seven variables are also displayed in Table 1. Satisfaction was related to lower levels of worry concerning future competence, disengagement, experienced workload, exhaustion and lack of interest. Furthermore, the more students reported disengagement, the more they experienced worry, workload, exhaustion and lack of interest. Workload was also related to higher levels of worry, exhaustion and lack of interest, and to lower levels of received feedback. Exhaustion and lack of interest also correlated positively with each other. Academic self-concept had negative correlations with both lack of interest and workload.

The reliability of the seven latent constructs was assessed using coefficient H (Hancock \& Mueller, 2001), which measures the degree of replicability of a construct based on its measured indicators. The cut off value of 0.70 has been used for a good reliability. As can be seen in Table 1, construct reliability values ranged from 0.64 to 0.89 , reflecting acceptable construct reliability.

Confirmatory factor analysis demonstrated that HESI factor structure appeared adequate. The chi-square statistic was statistically significant $\left(\chi^{2}[109, \mathrm{n}=610]=275.1, p<0.001\right)$, but the ratio was smaller than 3.0 (i.e. 2.5). Furthermore, results showed a CFI of 0.90 , TLI of 0.87 and a RMSEA of 0.050 (90\% CI: $0.043-0.057$ ). Therefore, the HESI factorial structure was considered adequate. 
Preceding the MANOVA-analysis, the data were screened for independence of observations, normality and homogeneity of the covariances. The observations were independent because each student filled out the questionnaire independently of the others. All dependent measures met the normality criterion. Box's test of equality of covariance matrices was significant (Box's $\mathrm{M}=148.8, p=0.011$ ), but as noted by Tabachnick \& Fidell (2007) the test is highly sensitive and covariances can be treated as equal unless $p$ level is below $p<0.001$. We therefore concluded that the assumption of equal covariances was met.

\subsection{Relationships between Perceptions of the Learning Environment, Lack of Interest, Exhaustion, and Academic Self-Concept}

After confirming the factor structure of the HESI scales measuring students' perceptions of their learning environment, a structural equation model was used to test the relationships between these perceptions with lack of interest, exhaustion, and academic self-concept. As presented in Figure 1, the model tested whether exhaustion and lack of interest mediated the relationship between perceptions of the learning environment and academic self-concept. Academic self-concept reflected the perception of self in the educational environment. As a result of the fit between the learner and the learning environment, it was chosen as the dependent variable in the model. Only students who had answered the item about academic self-concept $(\mathrm{n}=582)$ were included in the analysis. The model yielded a reasonable fit. The chi-square test was statistically significant $\left(\chi^{2}[226, \mathrm{n}=582]=516.9, p\right.$ $<0.001$ ), but the ratio was smaller than 3.0 (i.e. 2.3). Results furthermore showed a CFI of 0.91, a TLI of 0.89 and a RMSEA of 0.047 (90\% CI: $0.042-0.052$ ).

The results of the structural model are summarised in Figure 1. Worry and even more strongly, workload were positively significantly related to exhaustion. Worry and satisfaction were negatively related to lack of interest, whereas workload was positively related to it. Regarding any learning environment perceptions, only workload was related to academic self-concept. Exhaustion was positively, and lack of interest negatively related to academic self-concept.

Finally, a model without direct paths from students' perceptions to academic self-concept was compared with the hypothesized model as suggested by Figure 1. This was done to examine whether relations between students' perceptions of the learning environment and the academic self-concept are completely mediated by exhaustion and lack of interest. This alternative model was identical to the model in Figure 1, but it did not assume direct paths from the perceptions directly to academic self-concept. This alternative model resulted in a model with 231 degrees of freedom. The value of $\Delta \chi^{2}(\mathrm{df}=5)=15.94$, was significant at the .01 level, assuming partial mediation. In other words, adding direct relations between conceptions and processing variables lead to a better explanation of the data compared to complete mediation. Therefore, relations between perceptions of the learn-

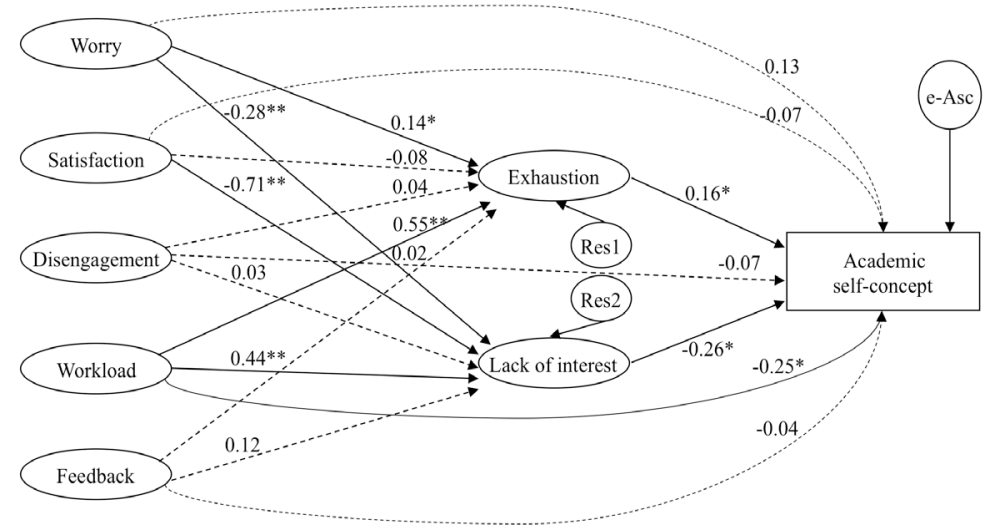

Only latent variables, residual errors and achievement variables are presented. Dotted lines are non-significant paths.

Res $=$ residual; error in the prediction of endogenous factors from exogenous factors.

Figure 1. Parameter estimates (standardized regression coefficients) for the structural equation model of the linear relationships between students' perceptions of the learning environment, exhaustion, lack of interest and academic self-concept $(n=582)$. 
ing environment and the academic self-concept are only partially mediated by students' exhaustion and lack of interest.

\subsection{Comparing LBL and PBL Curricula}

Results of the MANOVA showed significant differences on the dependent measures between the lecture-based and problem-based curricula [Wilks's $\Lambda=0.93, \mathrm{~F}(8,571)=5.19, p<0.001, p \eta_{p}{ }^{2}=0.068$ ] as well as between different programme years [Wilks's $\left.\Lambda=0.92, \mathrm{~F}(8,571)=6.65, p<0.001, p \eta_{p}{ }^{2}=0.085\right]$. The interaction effect of the two independent variables was also significant [Wilks's $\Lambda=0.97, F(8,571)=2.43, p=0.014, \eta_{p}{ }^{2}=$ 0.033].

Univariate results showed significant differences between the different curricula. PBL students experienced more worry $\left[\mathrm{F}(1)=5.39, p=0.021, \eta^{2}=0.009\right.$; MD PBL $\left.-\mathrm{LBL}=0.17\right]$, receiving more feedback $[\mathrm{F}(1)=6.96$, $\left.p=0.009, \eta_{p}{ }^{2}=0.012 ; \mathrm{MD} \mathrm{PBL}-\mathrm{LBL}=0.15\right]$, more exhaustion $\left[\mathrm{F}(1)=8.45, p=0.004, \eta^{2}=0.014\right.$; MD PBL $-\mathrm{LBL}=0.24]$ and higher levels of academic self-concept $\left[\mathrm{F}(1)=6.08, p=0.014, \eta_{p}{ }^{2}=0.010 ; \mathrm{MD} \mathrm{PBL}-\mathrm{LBL}\right.$ $=0.15]$.

Differences concerning satisfaction and workload also existed between the pre-clinical phase and clinical phase of students' study. Students in the pre-clinical phase reported more satisfaction $[\mathrm{F}(1)=11.95, p=0.001$, $\left.\eta^{2}=0.020 ; \mathrm{MD} \mathrm{PreCl}-\mathrm{PostCl}=0.12\right]$ and more workload $\left[\mathrm{F}(1)=13.74, p<0.001, \eta^{2}=0.023 ; \mathrm{MD}\right.$ PreCl PostCl $=0.18]$.

The interaction effect appeared significant for exhaustion $\left[\mathrm{F}(1)=7.24, p=0.007, \eta_{p}{ }^{2}=0.012\right]$ and academic self-concept $\left[\mathrm{F}(1)=7.05, p=0.008, \eta_{p}{ }^{2}=0.012\right]$. As can be seen in Table 2, PBL students experienced more exhaustion during their pre-clinical phase compared to LBL students, but not during their clinical years. Table 2 also shows a similar pattern for academic self-concept. It was significantly higher in the pre-clinical phase for the PBL group, but this difference disappeared in the clinical phase.

\section{Discussion}

Our present study investigated students' experiences of their learning environment in relation to reported exhaustion, lack of interest and academic self-concept. We particularly examined 1) how experiences of the learning environment were related to exhaustion, lack of interest and academic self-concept and 2) how these experiences differed between PBL and LBL medical schools and different study phases (preclinical/novice, clinical/advanced). It was assumed that worry about future competence would positively relate to exhaustion and satisfaction with the learning environment would negatively relate to it. We also anticipated that lack of interest would negatively relate to academic self-concept. Concerning differences between medical schools our hypothesis was that students in the PBL environment would experience more workload and exhaustion at the beginning of their studies. We also anticipated that students in the PBL environment would experience receiving more feedback.

Table 2. Means and standard deviations of the eight dependent variables in two medical schools and two phases of studies.

\begin{tabular}{|c|c|c|c|c|c|c|c|c|c|}
\hline \multirow[b]{3}{*}{ Variable } & \multirow[b]{3}{*}{ Range } & \multicolumn{4}{|c|}{ Lecture-Based (LBL) } & \multicolumn{4}{|c|}{ Problem-Based (PBL) } \\
\hline & & \multicolumn{2}{|c|}{ Pre-Clinical } & \multicolumn{2}{|c|}{ Clinical } & \multicolumn{2}{|c|}{ Pre-Clinical } & \multicolumn{2}{|c|}{ Clinical } \\
\hline & & M & $\mathrm{SD}$ & M & $\mathrm{SD}$ & M & $\mathrm{SD}$ & M & SD \\
\hline Worry & $1-4$ & 2.70 & 0.72 & 2.81 & 0.81 & 2.92 & 0.75 & 2.92 & 0.70 \\
\hline Satisfaction & $1-4$ & 3.42 & 0.38 & 3.32 & 0.40 & 3.40 & 0.31 & 3.27 & 0.38 \\
\hline Disengagement & $1-4$ & 1.69 & 0.49 & 1.74 & 0.50 & 1.60 & 0.39 & 1.66 & 0.42 \\
\hline Workload & $1-4$ & 2.15 & 0.63 & 2.04 & 0.70 & 2.30 & 0.75 & 1.95 & 0.64 \\
\hline Feedback & $1-4$ & 1.93 & 0.64 & 1.96 & 0.62 & 2.01 & 0.65 & 2.18 & 0.59 \\
\hline Exhaustion & $1-5$ & 2.48 & 0.85 & 2.60 & 0.90 & 2.92 & 0.78 & 2.62 & 0.87 \\
\hline Lack of Interest & $1-5$ & 1.88 & 0.88 & 1.74 & 0.80 & 1.74 & 0.72 & 1.68 & 0.81 \\
\hline $\begin{array}{c}\text { Academic } \\
\text { Self-Concept }\end{array}$ & $1-3$ & 2.04 & 0.70 & 2.11 & 0.61 & 2.35 & 0.63 & 2.10 & 0.69 \\
\hline
\end{tabular}


Construct reliability values of the HESI scales gave evidence of good reliability in terms of internal consistency. Based on the reliability measures and confirmatory factor analysis of the present data, students were able to distinguish between the five different perceptions of the learning environment and the HESI scales were adequate measures of learning environment perceptions in the used sample. Students' experiences of their learning environment have been studied using various instruments (Fraser, 1998). In medical education, one widely used measurement tool is DREEM (Dundee Ready Education Environment Measure) (Miles et al., 2012; Roff et al., 1997). Although originally it was considered a generic and culturally independent instrument (Roff, 2005), problems with internal consistency have been found even when comparing culturally similar groups (Hammond et al., 2012). It is therefore important to assure the suitability of the used measurement in our study sample and the present results seem to suggest this was the case.

Relations between perceptions of the learning environment, early signs of burnout (i.e. exhaustion and lack of interest) and academic self-concept were examined with a structural equation model. Workload and worry about future endurance were related to exhaustion, which was in line with our hypothesis. This result is in line with earlier findings concerning the unfavourable effects of a high perceived workload (Guthrie et al., 1995; Wolf et al., 1988) and worries about future competence (Dahlin et al., 2010) on students' well-being. The strong negative relation between satisfaction and lack of interest corresponded with our second hypothesis. If a medical student loses interest or experiences feelings of cynicism already during his or her studies, chances are this will continue during working life (Dahlin et al., 2010; Salmela-Aro et al., 2009).

The negative relation between worry about future competence and lack of interest was rather surprising. It could be argued that worry about personal competence and workload in the future profession reflects commitment to this profession, which would relate to a higher interest (i.e. lower levels of lack of interest). It could be a sign of devotion and high ethical standards: concentrating on personal competence and skills is probably a good motivator for continuous development in the long run. The positive relation between exhaustion and academic self-concept is probably in line with this, reflecting high standards and working moral. While some amount of challenge and workload is needed for effectively focusing attention, excessive demands however are not desirable (Kember \& Leung, 2006). Prolonged worry and exhaustion may result in problems with occupational health.

Disengagement and feedback did not relate to either exhaustion or lack of interest. The HESI scale for disengagement focuses on anonymity and competition among students and on whether the professional role in education is in conflict with students' personal values. Feedback refers to whether students receive encouragement or feedback from their teachers. Although disengagement and feedback are important aspects of study conditions, in our study they appeared separate from experiences of exhaustion and losing interest in personal studies. The $\Delta \chi^{2}$ tests supported partial mediation between the perceptions of the learning environment and academic selfconcept by exhaustion and lack of interest. Therefore, relations between perceptions of the learning environment and the academic self-concept are only partially mediated by students' exhaustion and lack of interest.

Students in the pre-clinical phase of their studies experienced more workload and satisfaction than students in later phases of their studies. At the beginning of their studies students need to make an effort and learn new strategies to help grasp extensive amounts of information resulting in increased workload. During the pre-clinical phase students have predefined lessons and practical sessions, and the programme may seem structured and easier to comprehend. Dealing with the uncertainty and emotional complexity of working with real medical casesduring the clinical phase requires adjustment from the student, which may lead to more dissatisfaction. Moreover, experiences of being treated unfairly have been found to be most common during the clinical phase of studies (Elnicki et al., 2002).

The PBL curriculum appeared an engaging but challenging environment for novice students. As we expected, PBL students reported more exhaustion than their peers in the non-PBL group at the beginning of their studies. During this time, PBL students may be forced to work at the upper limits of their skills. In addition, PBL students reported higher levels of concern for their studies than students in the lecture-based group. This concurs with findings by Moffat et al. (2004) about uncertainty in study behaviour, progress, aptitude and assessment and by Lewis et al. (2009) about PBL students feeling uncertain about what is expected of them by the faculty and experiencing the curriculum as unclear. PBL students, however, also reported higher levels of academic self-concept in the pre-clinical phase of their studies. In line with our hypothesis they also experienced receiving more feedback. Contrary to our hypothesis, there was no difference in the level of experienced workload. 
Studies comparing students' experiences in LBL and PBL environments have been scarce, their results mixed and more studies are needed to detect the curricular factors that play a role in student well-being (Dyrbye et al., 2006). Our study adds to this and suggests that PBL students may feel somewhat overwhelmed at the beginning of their studies. Novel settings produce negative emotions for learners, because they are not yet able to achieve the required degree of self-regulation (Lindblom-Ylänne \& Lonka, 2000; Pekrun, 2006; White et al., 2014). For example, some amount of stress is needed for effectively focusing attention, but excessive stress leads to a loss of concentration (Kember \& Leung, 2006). A cross-sectional design was used in our present study, which places restrictions on result interpretation. Future research using a longitudinal design could shed light on developmental paths. It should also be noticed that in addition to differences related to lecture-based and problem-based curricula, other factors also play a role in how students experience their learning environment. Faculty size, physical features of the building, atmosphere, group cohesion among students and student selection criteria are factors that may affect students' observations and well-being (Genn, 2001). Dealing with this complexity has to be accepted, because random control trials are not an option when comparing the long-term effects of the learning environment.

\section{Conclusion}

In conclusion, this paper investigated how students' perceptions of the learning environment are connected with their well-being and academic self-concept. Additionally, it was examined whether traditional, lecture-based and more student-centered problem-based learning environments differ in this respect.

Given the present findings, students' well-being might be increased by tackling their experiences of high workload and worry about their current and future stress. At the beginning of their studies, this might be facilitated by helping students obtain necessary study skills for dealing with complex and extensive amounts of information. To prevent problems later on during their career, it is advisable to be aware of the early signs of burnout that begin developing during medical school. It would also be important to find ways to deal with their career choice satisfaction and how education prepares them for it. It seems that although PBL and other novel teaching methods are likely to be beneficial in the long term, at first they may be burdening. High challenge and experience of exhaustion may be an essential part of the process of gradually learning to take responsibility for the learning process.

\section{Acknowledgements}

This study was funded by The Finnish Funding Agency for Technology and Innovation (Tekes) RYM Indoor Environment project (Project Number 462054) and by the Academy of Finland project Mind the Gap (Project Number 1265528). We are thankful for the support we have received.

\section{References}

Abdulghani, H. M., Al-Drees, A. A., Khalil, M. S., Ahmad, F., Ponnamperuma, G. G., \& Amin, Z. (2014). What Factors Determine Academic Achievement in High Achieving Undergraduate Medical Students? A Qualitative Study. Medical Teacher, 36, S43-S48. http://dx.doi.org/10.3109/0142159X.2014.886011

Benbassat, J. (2014). Changes in Wellbeing and Professional Values among Medical Undergraduate Students: A Narrative Review of the Literature. Advances in Health Sciences Education, 19, 597-610. http://dx.doi.org/10.1007/s10459-014-9500-1

Bentler, P. (1990). Comparative Fit Indexes in Structural Models. Psychological Bulletin, 107, 238-246. http://dx.doi.org/10.1037/0033-2909.107.2.238

Bong, M., \& Skaalvik, E. M. (2003). Academic Self-Concept and Self-Efficacy: How Different Are They Really? Educational Psychology Review, 15, 1-40. http://dx.doi.org/10.1023/A:1021302408382

Browne, M. W., \& Cudeck, R. (1993). Multifaceted Conceptions of Fit in Structural Equation Models. In K. A. Bollen, \& J. S. Long (Eds.), Testing Structural Equation Models (pp. 137-162). Newbury Park, CA: Sage.

Camp, D. L., Hollingsworth, M. A., Zaccaro, D. J., Cariaga-Lo, L. D., \& Richards, B. F. (1994). Does a Problem-Based Learning Curriculum Affect Depression in Medical Students? Academic Medicine: Journal of the Association of American Medical Colleges, 69, S25-S27. http://dx.doi.org/10.1097/00001888-199410000-00031

Cohen, J. (1988). Statistical Power Analysis for the Behavioral Sciences. Hillsdale, NJ: Lawrence Erlbaum. 
Dahlin, M. (2007). Future Doctors: Mental Distress during Medical Education: Cross-Sectional and Longitudinal Studies. Stockholm: Karolinska University Press.

Dahlin, M., Joneborg, N., \& Runeson, B. (2005). Stress and Depression among Medical Students: A Cross-Sectional Study. Medical Education, 39, 594-604. http://dx.doi.org/10.1111/j.1365-2929.2005.02176.x

Dahlin, M., Fjell, J., \& Runeson, B. (2010). Factors at Medical School and Work Related to Exhaustion among Physicians in Their First Postgraduate Year. Nordic Journal of Psychiatry, 64, 402-408. http://dx.doi.org/10.3109/08039481003759219

Dyrbye, L. N., Thomas, M. R., Harper, W., Massie Jr., F. S., Power, D. V., Eacker, A., Szydlo, D. W., Novotny, P. J., Sloan, J. A., \& Shanafelt, T. D. (2009). The Learning Environment and Medical Student Burnout: A Multicentre Study. Medical Education, 43, 274-282. http://dx.doi.org/10.1111/j.1365-2923.2008.03282.x

Dyrbye, L. N., Thomas, M. R., \& Shanafelt, T. D. (2006). Systematic Review of Depression, Anxiety, and Other Indicators of Psychological Distress among U.S. and Canadian Medical Students. Academic Medicine, 81, 354-373. http://dx.doi.org/10.1097/00001888-200604000-00009

Elnicki, D. M., Curry, R. H., Fagan, M., Friedman, E., Jacobson, E., Loftus, T., Ogden, P., Pangaro, L., Papadakis, M., Szauter, K., Wallach, P., \& Linger, B. (2002). Medical Students' Perspectives on and Responses to Abuse during the Internal Medicine Clerkship. Teaching and Learning in Medicine, 14, 92-97. http://dx.doi.org/10.1207/S15328015TLM1402_05

Fidell, L. S., \& Tabachnick, B. G. (2007). Using Multivariate Statistics. Boston, MA: Pearson Allyn and Bacon.

Fraser, B. J. (1998). Science Learning Environments: Assessment, Effects and Determinants. In B. J. Fraser, \& K. G. Tobin (Eds.), International Handbook of Science Education (pp. 527-561). Dordrecht: Kluwer Academic Publishers. http://dx.doi.org/10.1007/978-94-011-4940-2_31

Genn, J. M. (2001). AMEE Medical Education Guide No. 23 (Part 2): Curriculum, Environment, Climate, Quality and Change in Medical Education-A Unifying Perspective. Medical Teacher, 23, 445-454.

Guthrie, E. A., Black, D., Shaw, C. M., Hamilton, J., Creed, F. H., \& Tomenson, B. (1995). Embarking upon a Medical Career: Psychological Morbidity in First Year Medical Students. Medical Education, 29, 337-341. http://dx.doi.org/10.1111/j.1365-2923.1995.tb00022.x

Hammond, S. M., O’Rourke, M., Kelly, M., Bennett, D., \& O’Flynn, S. (2012). A Psychometric Appraisal of the DREEM. BMC Medical Education, 12, 2. http://dx.doi.org/10.1186/1472-6920-12-2

Hancock, G. R., \& Mueller, R. O. (2001). Rethinking Construct Reliability within Latent Variable Systems. In R. Cudeck, S. du Toit, \& D. Sörbom (Eds.), Structural Equation Modeling: Present und Future-A Festschrift in Honor of Karl Joreskog (pp. 195-216). Lincolnwood, IL: Scientific Software International.

Hansford, B. C., \& Hattie, J. A. (1982). The Relationship between Self and Achievement/Performance Measures. Review of Educational Research, 52, 123-142. http://dx.doi.org/10.3102/00346543052001123

Kember, D., \& Leung, D. Y. P. (2006). Characterising a Teaching and Learning Environment Conducive to Making Demands on Students While Not Making Their Workload Excessive. Studies in Higher Education, 31, 185-198. http://dx.doi.org/10.1080/03075070600572074

Kiessling, C., Schubert, B., Scheffner, D., \& Burger, W. (2004). First Year Medical Students' Perceptions of Stress and Support: A Comparison between Reformed and Traditional Track Curricula. Medical Education, 38, 504-509. http://dx.doi.org/10.1046/j.1365-2929.2004.01816.x

Kline, R. B. (2005). Principles and Practice of Structural Equation Modeling (2nd ed.). New York: Guilford Press.

Krakowski, A. J. (1982). Stress and the Practice of Medicine-The Myth and Reality. Journal of Psychosomatic Research, 26, 91-98. http://dx.doi.org/10.1016/0022-3999(82)90068-X

Lewis, A. D., Menezes, D. A., McDermott, H. E., Hibbert, L. J., Brennan, S. L., Ross, E. E., \& Jones, L. A. (2009). A Comparison of Course-Related Stressors in Undergraduate Problem-Based Learning (PBL) versus Non-PBL Medical Programmes. BMC Medical Education, 9, 60. http://dx.doi.org/10.1186/1472-6920-9-60

Lindblom-Ylänne, S., \& Lonka, K. (2000). Interaction between Learning Environment and Expert Learning. Lifelong Learning in Europe, 5, 90-97.

Lonka, K., Sharafi, P., Karlgren, K., Masiello, I., Nieminen, J., Birgegard, G., \& Josephson, A. (2008). MED NORD—A Tool for Measuring Medical Students' Well-Being and Study Orientations. Medical Teacher, 30, 72-79. http://dx.doi.org/10.1080/01421590701769555

Loyens, S. M. M., Rikers, R. M. J. P., \& Schmidt, H. G. (2009). Students' Conceptions of Constructivist Learning in Different Programme Years and Different Learning Environments. British Journal of Educational Psychology, 79, 501-514. http://dx.doi.org/10.1348/000709908X378117

Ma, X., \& Kishor, N. (1997). Attitude toward Self, Social Factors, and Achievement in Mathematics: A Meta-Analytic Re- 
view. Educational Psychology Review, 9, 89-120. http://dx.doi.org/10.1023/A:1024785812050

Mäkinen, J., Olkinuora, E., \& Lonka, K. (2004). Students at Risk: Students' General Study Orientations and Abandoning/Prolonging the Course of Studies. Higher Education: The International Journal of Higher Education and Educational Planning, 48, 173-188. http://dx.doi.org/10.1023/B:HIGH.0000034312.79289.ab

Marsh, H. W. (1987). The Big-Fish-Little-Pond Effect on Academic Self-Concept. Journal of Educational Psychology, 79, 280-295. http://dx.doi.org/10.1037/0022-0663.79.3.280

Maslach, C., \& Jackson, S. E. (1981). The Measurement of Experienced Burnout. Journal of Occupational Behaviour, 2 , 99-113.

Miles, S., Swift, L., \& Leinster, S. J. (2012). The Dundee Ready Education Environment Measure (DREEM): A Review of Its Adoption and Use. Medical Teacher, 34, e620-e634. http://dx.doi.org/10.3109/0142159X.2012.668625

Moffat, K. J., McConnachie, A., Ross, S., \& Morrison, J. M. (2004). First Year Medical Student Stress and Coping in a Problem-Based Learning Medical Curriculum. Medical Education, 38, 482-491.

http://dx.doi.org/10.1046/j.1365-2929.2004.01814.x

Nieminen, J. (2011). Dimensions of University Student Learning in Medicine and Pharmacy. Helsinki: University of Helsinki.

Pekrun, R. (2006). The Control-Value Theory of Achievement Emotions: Assumptions, Corollaries, and Implications for Educational Research and Practice. Educational Psychology Review, 18, 315-341. http://dx.doi.org/10.1007/s10648-006-9029-9

Roff, S. (2005). The Dundee Ready Educational Environment Measure (DREEM)—a Generic Instrument for Measuring Students' Perceptions of Undergraduate Health Professions Curricula. Medical Teacher, 27, 322-325. http://dx.doi.org/10.1080/01421590500151054

Roff, S., McAleer, S., Harden, R. M., Al-Qahtani, M., Ahmed, A. U., Deza, H., Groenen, G., \& Primparyon, P. (1997). Development and Validation of the Dundee Ready Education Environment Measure (DREEM). Medical Teacher, 19, 295299. http://dx.doi.org/10.3109/01421599709034208

Salanova, M., Schaufeli, W., Martínez, I., \& Bresó, E. (2010). How Obstacles and Facilitators Predict Academic Performance: The Mediating Role of Study Burnout and Engagement. Anxiety, Stress \& Coping, 23, 53-70. http://dx.doi.org/10.1080/10615800802609965

Salmela-Aro, K., \& Kunttu, K. (2010). Study Burnout and Engagement in Higher Education. Unterrichtswissenschaft, 38, 318-333.

Salmela-Aro, K., Tolvanen, A., \& Nurmi, J. (2009). Achievement Strategies during University Studies Predict Early Career Burnout and Engagement. Journal of Vocational Behavior, 75, 162-172. http://dx.doi.org/10.1016/j.jvb.2009.03.009

Schmidt, H. G. (1983). Problem-Based Learning: Rationale and Description. Medical Education, 17, 11-16. http://dx.doi.org/10.1111/j.1365-2923.1983.tb01086.x

Schmidt, H. G., Cohen-Schotanus, J., \& Arends, L. R. (2009). Impact of Problem-Based, Active Learning on Graduation Rates for 10 Generations of Dutch Medical Students. Medical Education, 43, 211-218.

http://dx.doi.org/10.1111/j.1365-2923.2008.03287.x

Schreiber, J. B., Nora, A., Stage, F. K., Barlow, E. A., \& King, J. (2006). Reporting Structural Equation Modeling and Confirmatory Factor Analysis Results: A Review. Journal of Educational Research, 99, 323-338. http://dx.doi.org/10.3200/JOER.99.6.323-338

Shanafelt, T. D., Sloan, J. A., \& Habermann, T. M. (2003). The Well-Being of Physicians. The American Journal of Medicine, 114, 513-519. http://dx.doi.org/10.1016/S0002-9343(03)00117-7

Skaalvik, E. M. (1997). Self-Enhancing and Self-Defeating Ego Orientation: Relations with Task and Avoidance Orientation, Achievement, Self-Perceptions, and Anxiety. Journal of Educational Psychology, 89, 71-81.

http://dx.doi.org/10.1037/0022-0663.89.1.71

Skaalvik, E. M., \& Rankin, R. J. (1995). A Test of the Internal/External Frame of Reference Model at Different Levels of Math and Verbal Self-Perception. American Educational Research Journal, 32, 161-184. http://dx.doi.org/10.3102/00028312032001161

Stewart, S. M., Lam, T. H., Betson, C. L., Wong, C. M., \& Wong, A. M. (1999). A Prospective Analysis of Stress and Academic Performance in the First Two Years of Medical School. Medical Education, 33, 243-250. http://dx.doi.org/10.1046/j.1365-2923.1999.00294.x

Stubb, J., Pyhältö, K., \& Lonka, K. (2012). The Experienced Meaning of Working with a PhD Thesis. Scandinavian Journal of Educational Research, 56, 439-456. http://dx.doi.org/10.1080/00313831.2011.599422 
Taris, T. W. (2006). Is There a Relationship between Burnout and Objective Performance? A Critical Review of 16 Studies. Work \& Stress, 20, 316-334. http://dx.doi.org/10.1080/02678370601065893

Thomas, M. R., Dyrbye, L. N., Huntington, J. L., Lawson, K. L., Novotny, P. J., Sloan, J. A., \& Shanafelt, T. D. (2007). How Do Distress and Well-Being Relate to Medical Student Empathy? A Multicenter Study. Journal of General Internal Medicine, 22, 177-183. http://dx.doi.org/10.1007/s11606-006-0039-6

Tucker, L. R., \& Lewis, C. (1973). A Reliability Coefficient for Maximum Likelihood Factor Analysis. Psychometrika, 38, 1-10. http://dx.doi.org/10.1007/BF02291170

Tyssen, R., Vaglum, P., Grønvold, N. T., \& Ekeberg, Ø. (2005). The Relative Importance of Individual and Organizational Factors for the Prevention of Job Stress during Internship: A Nationwide and Prospective Study. Medical Teacher, 27, 726-731. http://dx.doi.org/10.1080/01421590500314561

WFME (2003). Basic Medical Education. WFME Global Standards for Quality Improvement. Copenhagen: WFME.

White, C., Bradley, E., Martindale, J., Roy, P., Patel, K., Yoon, M., \& Worden, M. K. (2014). Why Are Medical Students 'Checking out' of Active Learning in a New Curriculum? Medical Education, 48, 315-324. http://dx.doi.org/10.1111/medu.12356

Wolf, T. M., Balson, P. M., Faucett, J. M., \& Randall, H. M. (1989). A Retrospective Study of Attitude Change during Medical Education. Medical Education, 23, 19-23. http://dx.doi.org/10.1111/j.1365-2923.1989.tb00807.x

Wolf, T. M., Faucett, J. M., Randall, H. M., \& Balson, P. M. (1988). Graduating Medical Students' Ratings of Stresses, Pleasures, and Coping Strategies. Journal of Medical Education, 63, 636-642. 
Scientific Research Publishing (SCIRP) is one of the largest Open Access journal publishers. It is currently publishing more than 200 open access, online, peer-reviewed journals covering a wide range of academic disciplines. SCIRP serves the worldwide academic communities and contributes to the progress and application of science with its publication.

Other selected journals from SCIRP are listed as below. Submit your manuscript to us via either submit@scirp.org or Online Submission Portal.
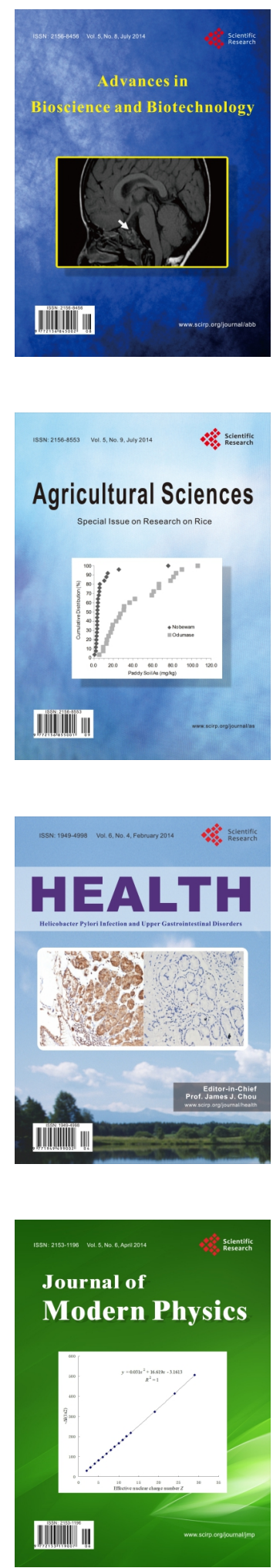
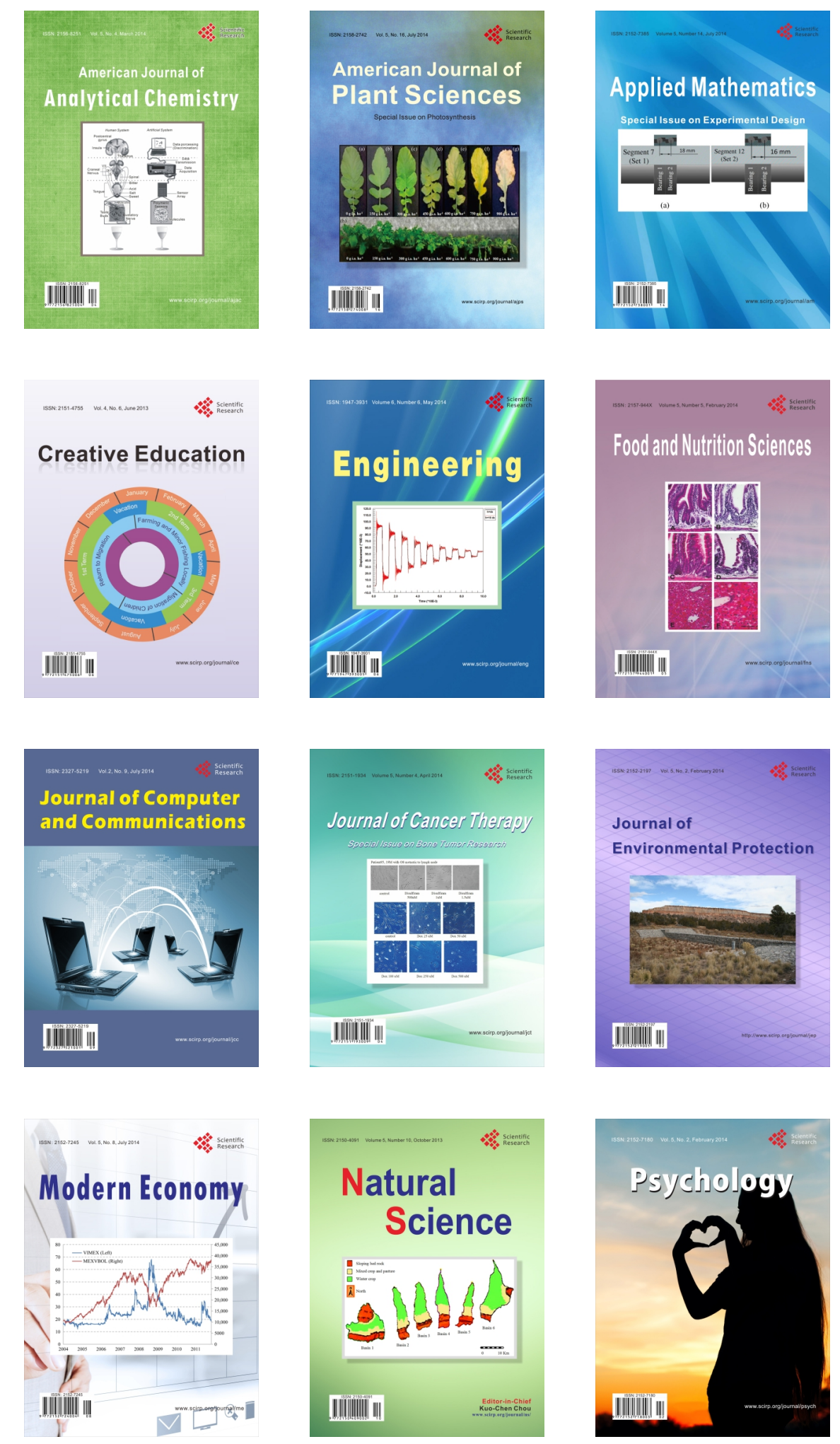